\title{
Developing Digital Information Literacy in Higher Education: Obstacles and Supports
}

\author{
Lynn Jeffrey \\ Massey University, Auckland, \\ New Zealand \\ I.m.jeffrey@massey.ac.nz
}

\author{
Bronwyn Hegarty \\ Otago Polytechnic, Dunedin, \\ New Zealand \\ bronwyn.hegarty@gmail.com
}

\author{
Oriel Kelly \\ Manakau Institute of Technology, Auckland, New Zealand \\ oriel.kelly@manukau.ac.nz
}
Merrolee Penman, Dawn Coburn, and Jenny McDonald Otago University, Dunedin, New Zealand
Merrolee.Penman@op.ac.nz; dawncoburn1@gmail.com;
jenny.mcdonald@otago.ac.nz

\section{Executive Summary}

The development of digital information literacy (DIL) has been slow in comparison to changes in information communication technologies, and this remains an issue for the higher education sector. Competency in such skills is essential to full participation in society and work. In addition, these skills are regarded as underpinning the ability to maintain life long learning. Evidence suggests that simple exposure to technology is not sufficient to promote adequate levels of literacy.

Why has DIL development been so slow? How can we speed the process up? The purpose of this study was to identify obstacles and supports to fostering the development of DIL to staff and students in higher education.

The literature identified a range of obstacles that hindered students' ability to develop their technology related skills. The issue of access and the digital divide that has been of interest to those concerned with social equity continues to generate lively discussion. The students' own beliefs and attitudes to learning new technology can also become barriers to the students' learning progress when they experience low self-efficacy or anxiety about their ability to develop digital

skills. Conversely, students who are

Material published as part of this publication, either on-line or in print, is copyrighted by the Informing Science Institute. Permission to make digital or paper copy of part or all of these works for personal or classroom use is granted without fee provided that the copies are not made or distributed for profit or commercial advantage AND that copies 1) bear this notice in full and 2) give the full citation on the first page. It is permissible to abstract these works so long as credit is given. To copy in all other cases or to republish or to post on a server or to redistribute to lists requires specific permission and payment of a fee. Contact HPublisher@InformingScience.orgH to request redistribution permission. over-confident regarding their technical proficiency can also be hindered in their ability to develop good digital information skills.

Three broad strategies were inferred from the learning principles advocated nearly 80 years ago by Dewey as having the potential to support the development of digital information skills. The first of these was collaboration and sharing. 
While the benefits of collaboration were established decades ago, the advent of the Internet has made this a reality through online communities of practice. Dewey's advocacy of experiential learning has been widely applied on the Internet in the form of bricolage. Finally, personal relevance, the third of Dewey's principles, is an inherent part of the Web 2. 0 tools that personalize online environments to the individual.

Using a case study design, four higher education institutions ran 10 two-hour workshops in which participants were given autonomy over their learning and goals and were encouraged to collaborate and to engage in explorative trial-and-error learning.

Results indicated that these conditions nurtured and empowered participants. In addition, obstacles such as low self-efficacy, low confidence, and negative attitudes to technology were substantially reduced. Participants developed new approaches to learning and experienced personal growth through reflective journals that documented their learning journey.

Keywords: digital information literacy, computer self-efficacy, collaborative learning, bricolage, experiential learning, learning obstacles.

\section{Introduction}

The development of digital information literacy (DIL) has been slow in comparison to changes in information communication technologies, and this remains an issue for the higher education sector (Duderstadt \& Womack, 2004). There is evidence that exposure to technology alone does not adequately develop digital information skills, and more complex factors such as education and attitude must be considered (see, for example,C. Brown, Murphy, \& Nanny, 2003; Eshet-Alkalai $\&$ Chajut, 2010). Having a digitally information literate population is important socially, economically, educationally, and globally (Ministry of Economic Development, 2008). Digital technology is such a pervasive influence in all aspects of modern living that it has become the key to meaningful participation in work and social activities (Ministry of Economic Development, 2008). These technologies are not only important to the way we work and socialise, they also have implications for how we learn and think, to the extent that "mastery of such tools is a critical element of what we know" (Saljo, 2010, p. 62). This becomes particularly significant when we take into account the widespread recognition of the importance of life long learning and the role digital technology might play in supporting such activity (American Library Association, 2006; OECD, 2004).

Digital technology is not new; a whole generation has grown up with this 'new' technology as an integral part of the way they live their lives (Prensky, 2001). The digital skills of the millennium generation and those from older age groups have mostly been developed outside the formal educational system; in the home or the workplace. The OECD report of 2006 found that students of most OECD countries had ready access to computers at school; however, it was at home that students mostly made use of their computers and developed their technical skills. As a result, students' "ICT-related competences grew exponentially, ... largely outperforming those of their teachers" (Pedro, 2007, p. 25). Consequently, the organic growth of digital literacy skills in the population has been ad hoc, uneven and largely determined by opportunities to learn (OECD, 2005). Given the large investment in educational technological infrastructure over the last 20 years, the failure to engage students in online learning and promote adequate development of DIL is discouraging (OECD, 2004).

The purpose of this study was to identify obstacles and support factors that influence the development of digital information literacy in staff and students in the tertiary education sector.

Issues of access, including technical, organizational and personal, present the major obstacles to becoming more proficient in digital information literacy. Almost 80 years after they were first 
Jeffrey, Hegarty, Kelly, Penman, Coburn, \& McDonald

propounded by Dewey (1933), three educational principles seem to have particular resonance in a digital learning environment: learning through experience, engagement in activities of personal relevance, and learning collaboratively.

\section{What does being Digitally Information Literate Mean?}

If, as suggested by Snyder, Angus, and Sutherland-Smith (2002), being digitally proficient is more than mere technical skills what additional skills are needed? This is a complex area, because it not only necessitates knowledge about literacy per se, but also requires the integration of several specific forms of literacy. This is because "in a technological society, literacy extends beyond the functional skills of reading, writing, speaking and listening to include multiple literacies such as visual, media, and information literacy" (The Centre for Literacy, n.d., para 2). The development of a concise definition of digital information literacy that captures these forms of literacy and satisfies the views of others' in the information field is problematic. Consequently, two definitions informed this study. The first was the Australia New Zealand Institute for Information Literacy (ANZILL) description of information literacy as "an intellectual framework for recognising the need for understanding, finding, evaluating, and using information" (Bundy, 2004, p. 4). The second definition was that of digital information fluency developed by the $21^{\text {st }}$ Century Information Fluency project (Heine \& O'Conner, n.d.):

Digital Information Fluency (DIF) is the ability to find, evaluate and use digital information effectively, efficiently and ethically. DIF involves Internet search skills that start with understanding how digital information is different from print information, knowing how to use specialized tools for finding digital information and strengthening the dispositions needed in the digital information environment.

Together, these definitions suggest that not only are the skills of accessing and using information regarded as important, but also the dispositions or characteristics required to be a capable user of information. Thus digital information literacy involves recognising the need for, and being able to access and evaluate electronic information. The digitally literate can confidently use, manage, create, quote, and share sources of digital information in an effective way that demonstrates an understanding and acknowledgement of the cultural, ethical, economic, legal, and social aspects of information.

Digital information literacy involves a multi-faceted approach to learning and is linked to strategies for independent learning and lifelong learning: aspects believed to be pre-requisites for information literacy and achieved by "leading individuals to think critically, and by helping them construct a framework for learning how to learn" (Bundy, 2004, p. 6.).

\section{Obstacles}

A number of factors impact on the access of users to digital information, including those that go beyond just the technologies available to users and the skills they have for using them (Pedro, 2007). For example, socio-economic standing as well as gender and age influence which technologies users are exposed to as part of their lifestyle, and the attitudes they have to the technologies can impact on skill development. A new digital divide is emerging within the Net Generation whereby those with higher socio-economic status are more likely to have a computer at home and access to a wide range of information and media when communicating with peers (Pedro, 2007). In addition, beliefs about one's own ability to learn, anxiety about learning, and confidence can hinder learning.

Self-efficacy is a context-specific belief about one's ability to effect a particular outcome (Bandura \& Cervone, 1986). It reflects the individual's perception of his or her ability based on past experiences, and it also influences future intentions and behaviour. The effect of academic 
self-efficacy on learning performance has been widely explored since Bandura's seminal work of the 1970's (see for example, Bandura, 1977; Pajares \& Miller, 1994).

More recently, research has examined the effect of self-efficacy on the use of technology. For example, Park and Chen (2007) argued that self-efficacy influenced peoples' perceptions about how easy new technology was to use and their intention to use it. Similarly, Cassidy and Eachus (2002) found that higher levels of computer self-efficacy in computer self-efficacy were associated with higher and more intense use of computers, and the exploration of a greater range of software. Others have also established a relationship between self-efficacy, attitude to technology, and the motivation to learn when faced with challenging situations (de Montigny, Cloutier, Ouellet, Courville, \& Rondeau, 2001; Milbrath \& Kinzie, 2000; Phelps, 2002; Phelps \& Graham, 2008; Piper \& Austin, 2004).

When looking at a range of factors, including enjoyment and learning goal orientation, Yi and Hwang (2003) found that several were associated with technology usage, including self-efficacy. Previously, Joo, Bong, and Choi (1998) had also found a direct relationship between Internet selfefficacy and the outcomes of learning. These findings were confirmed in a study on older women by Rosenthal (2010) who found two major obstacles to developing digital information literacy: anxiety/stress and a lack of self confidence. Anxiety and/or stress at the start of the learning programme was felt by nearly half the participants, while $36 \%$ reported low self confidence. Anxiety about learning to use technology is a specific manifestation of the effect that anxiety has long been known to have on learning performance, both during the learning process and in evaluations of learning (Tobias, 1985). Anxiety inhibits learning by diverting cognitive resources from the learning task to obsessing about the fears being experienced, thus reducing the individual's capacity to learn (Tobias, 1985). Specifically, computer anxiety acts as a barrier to using computers for learning (Bozionelos, 2004). Rosenthal's (2010) study echoes the work of Saade and Kira (2009) who also found that anxiety was closely related to self-efficacy and the perceived ease of use of technology.

However, overconfidence in one's digital abilities can also be a hindrance to developing new digital skills. A number of researchers argue that college students have high levels of confidence in their digital skills but are often unaware or do not recognize the importance of being able to evaluate the quality of information (C. Brown et al., 2003; Jenson, 2004; Manuel, 2002), an important aspect of information literacy (Bundy, 2004). For example, in the US, people between 18 and 29 are the heaviest users of the Internet for study, work, and leisure (Kohut et al., 2010). Many of them claim that the integral nature of technology in their lives is what distinguishes them from other generations. The empirical evidence seems to support this claim. Ninety percent of them use the Internet, $75 \%$ have social networks sites, and eight out of ten say they sleep with their mobile phones (Kohut et al., 2010). However, according to (Grant, Malloy, \& Murphy, 2009) this familiarity with technology seems to induce them to overestimate their skill.

Pedro (2007) claims that teachers are unable to acquire digital competency at a fast enough rate to remain ahead of their more technologically capable students. However, a study by Margaryan and Littlejohn (2008) found that students relied on their teachers to guide them in the use of appropriate technologies for learning, indicating a lack of understanding by students in how to use ICTs for learning. Even though the students were competent in using technologies in social networks such as Facebook, no correlation was found in Littlejohn, Margaryan, and Vojt's (2010) four year study between the ability to use technologies in social settings, and competence in using technologies for formal university learning. However, they claim, "Students who perceived they had better ICT skills were more likely to favour technology-supported learning" (p. 18). The inclusion of digital information literacies in the curricula is regarded by Littlejohn, Margaryan, and Vojt (2010) as important if learners are to keep up with the rapid technological change that is occurring globally. 
While those under 30 may regard themselves as technically proficient, there is evidence that their information literacy skills related to finding and critically evaluating information are less adequate (C. Brown et al., 2003; Jenson, 2004; Manuel, 2002). Even students with poor skills in online research were found by Jensen (2004) to be very confident of their search abilities. C. Brown et al. (2003) argue that the 'techno-savvy' image students have of themselves gives them a false sense of competence, and they fail to see a need for additional critical thinking skills. These skills which enable the individual to distinguish the biased or misleading from the reliable have been termed 'information literacy' (Eshet-Alkalai \& Chajut, 2010). Such information literacy skills are widely acknowledged as being essential to academic performance and employability and are particularly important in a digital context where information overload is an issue.

While some have argued that students lack the ability to properly evaluate online information (Janes, 2007; Jenson, 2004), others contend that students are as skeptical as adults about the quality of online information but are more concerned with finding and using information that fits a particular need, irrespective of its value (Metzger, Flanagin, \& Zwarun, 2003; Wang \& Artero, 2005). While these students may recognize the lack of credibility of information, they have not learned to appreciate the importance of quality information.

Eshet-Alkalai and Chajut (2010), in a study that measured changes in the digital information literacy of students (high school and college) and adults over a five-year period, found that exposure to and experience with technology improved technical skills. This was particularly true of the adults who almost wiped out the skill gap that had been apparent at the start of the five-year period between them and the group of students. Conversely, the study found that adults outperformed students on creative and critical skills in 2002, and five years later the size of that gap had increased. Younger people performed worse than they had five years previously on these particular information literacy skills.

This fall in information literacy over an extended period finds resonance with a 2009 report on national adult literacy in the US which documented a $9 \%$ decline in the ability of college students to understand complex prose in a study conducted between 1992 and 2003 (Baldi et al., 2009). At the same time Leu (1996) found that students using the Internet were easily distracted and would spend time searching for unrelated but 'cool' images or music. He found they were reluctant to read anything longer than a single word or sentence. Birkerts (1995) and Stoll (1995) also foreshadowed this trend when they warned that while traditional print-based materials encouraged deeper reading and understanding, digital materials led to a broader but more superficial appraisal of topics.

The decrease in information literacy reported in the literature appears to be at least partially related to the level of information bombardment experienced by those using the Internet. While a massive amount of information is made accessible, the user is left to choose which information is most suitable for the purpose. Q. Jones, Rafaeli, and Ravid (2004) argue that information overload is frequently dealt with by resorting to simpler responses to reduce the amount of cognitive effort. Eshet-Alkaai \& Geri (2007) go further and suggest that exposure to massive amounts of information eventually leads to a loss of the ability to think critically about the value of information. It has been argued that students need to be actively taught these information skills as they will not acquire them by simple exposure to digital information technologies (C. Brown, et al., 2003; Eshet-Alkalai \& Chajut, 2010; Marcum, 2002).

A final obstacle to becoming a more digitally literate society is the socio-economic issue of access to technology. This problem sparked the debate that has been termed the 'digital-divide' (Castells, 2001) There has been considerable concern that those from lower socio-economic groups would be disadvantaged by their lack of access to advanced technology at home, at work, and at school. Snyder et al. (2002) found the problem to be more complex than mere physical ac- 
cess. In a study of families from different socio-economic backgrounds who all had access to computers at home, they found that the use of the computer was dependent on family norms, values, and lifestyles. Children of families who placed a high premium on education had developed a broader range of literacy skills and these informed their use of the computer. Such families tended to come from higher socio-economic groups. Children from other families used the computer at home for entertainment but found using computers at school dull and uninspiring. While these students developed good technical skills for exploring the Internet, using email, participating in chatrooms and other entertainment, they lacked the skills and strategies essential for formal learning using digital tools. Access to computers at home did not improve their literacy achievement at school. Synder et al. (2002) concluded that 'access' needs to be reconceptualised to include the quality and nature of access.

\section{What are the Potential Solutions?}

The advent of the Internet has made possible the vision of John Dewey (1933) almost 80 years ago. Dewey was deeply critical of the school system at the time. He advocated three important principles: learning through experience; engagement in activities of personal relevance, and learning collaboratively. The technical capabilities of the Internet actively foster these principles. The Web 2.0 tools of social networking have encouraged collaboration and sharing of information. The ease of access to information has resulted in experiential learning by exploring and trial-anderror strategies (Tuckle, 1995). Finally, the generations born after the 1970s increasingly demand personal relevance in activities they are expected to undertake (Twenge, 2009). Twenge (2009) calls these the 'me' generation. Only when there are clear, immediate benefits are they likely to engage in learning. Whether this characteristic has resulted from their exposure to the Internet or some other influence is unclear. Personal relevance has long been known to be a significant factor in learning (Ashcroft, 1987). Internet search engines promote this principle by producing vast amounts of information for the surfer to select only that which is directly relevant. The synergy between Dewey's principles and the intuitive way in which people use the Internet suggest useful approaches to helping people develop their digital information skills.

\section{Collaboration and sharing}

The benefits of collaborative learning were established several decades ago (see for example, Gokhale, 1995); however, the technology of the Internet has provided the wherewithal to make this a reality. To date, the most successful collaborations have been in informal online learning communities, rather than in the formal education system where students strongly resent being forced to undertake group-work (Hunt, Eagle, \& Thomas, 2002).

Social networking has developed in recent years to encompass digitally networked tools that allow people to meet, interact, and share ideas, artifacts, and interests with each other (Anderson, 2009). A number of websites and applications are dedicated to supporting the practice and enable communities of learners to gather online, for example, MySpace, Facebook, Second Life, Open Sim, and LinkedIn. In addition, a multitude of sites have sprung up which support open sharing of information and networking based on the resources that are hosted on them, for example, Flickr for photo-sharing, Youtube and Blip.tv for video-sharing, and social bookmarking sites, such as Delicious.com and wikis. Increasingly, social networking applications are being used more formally in learning (Wilson, Ludwig-Hardman, Thornam, \& Dunlap, 2004) not only for online and distance teaching modes but also in face-to-face and blended modes. As a result, Anderson (2009) has altered his definition of social networking to become "networked tools that support and encourage learning through face-to-face and online interactions while retaining individual control over time, space, presence, activity and identity" (Anderson, 2009, para 1). 
Although social networking usually describes large-scale services such as Facebook, My Space, Twitter and blogs, the term can also refer to bounded networks such as elgg which tend to be for more restricted interest groups and professional communities (Anderson, 2009). An important feature of many networked sites and tools is their free and open nature, which has made it easy for non-experts to establish, manage, and participate in online interaction, and thus encourage collaborative output. A variation to the social networked communities is learning communities. The characteristics of a learning community were identified by Wilson et al., (2004) as:

- shared goals - provide common ground;

- safe and supportive conditions - based on trust, promotes risk-taking;

- collective identity - based on shared history;

- collaboration - interaction that results in learning from others;

- respectful inclusion - values and accommodates diversity;

- progressive discourse toward knowledge building - sharing and revising of views to come to a new understanding; and

- mutual appropriation - the dual role of members as both teachers and learners

The nature of online communities seems to foster sharing and collaboration (Bonk, 2009), providing a vehicle for knowledge development and learning which is playful (Tuckle, 1995).

\section{Bricolage: Experiential learning and play}

Dewey (1933) advocates experiential learning as a significant means of promoting learning. One embodiment of this that has gained currency on the Internet is bricolage (Tuckle, 1995). Bricolage is a broad term that covers a range of attributes. Papert (1998) drew attention to it as trialand-error learning where the student explores with whatever resources are to hand. J. S. Brown (2000) stresses the search for tools that are needed and the way they are used to build artifacts that have personal meaning. He contrasts bricolage to the linear, deductive, and abstract approach used in the formal education system. A number of writers extend the meaning to include learning through play (Tuckle, 1995). These various manifestations of bricolage all meet Dewey's criteria of 'experiential' learning.

In 1998, Papert claimed that children and students would lead the change to the way digital technology would eventually be used in the classroom. He believed that the strategies for learning that children developed exploring the Internet would create pressure for the adoption of those approaches in the formal education system. When using the Internet outside of the classroom, students connect and watch others, and then try themselves (C. Brown et al, 2003). Harel-Caperton (2003) echoes this view and recognizes that children manifest their learning through bricolage by exploring and exchanging ideas on the Internet. The notion of play in children's learning is not unusual. However, it seems that with the Internet, adults too are increasingly adopting this strategy as a legitimate means of engaging with new ideas, information, and problems. According to Tuckle (1995, p. 267), Internet users have "moved in the direction of accepting the postmodern values of opacity, playful experimentation, and navigation of surface as privileged ways of knowing".

The experiential and interactive components of using games for problem-solving in real-life situations have been found to be beneficial for learning because they enable progressive challenges and keep learners motivated through play and the construction of knowledge through "trial and error" (Chen \& Wang, 2009, p. 275). The context of play is an important component of using games to engage and motivate learners because it is associated with injecting fun into learning (Prensky, 2001). Additionally, immersion in play (when manipulating virtual environments such as The Sims) in combination with dialogue with others about those experiences has been shown 
to stimulate reflective learning both at a problem-solving level and at a deeper level through connection to real life situations (Hsiao, 2009).

\section{Personal relevance}

Dewey (1933) believed that students would learn better if what they were learning had personal relevance to them. Throughout the late $20^{\text {th }}$ century and early $21^{\text {st }}$ century researchers have rediscovered this truth. The constructivist movement has been at the forefront of promoting the importance of personal relevance to effective engagement, for example, Bransford, Sherwood, Hasselbring, Kinzer, and Williams (1990) pointed out that when students do not perceive relevance in knowledge, that knowledge becomes a fragile, inert cognitive structure that lacks context cues. Consequently, when later faced with a situation in which the knowledge may be applied, the student has no contextual cues to trigger a link between the problem and the knowledge. The humanistic view of teaching values student autonomy, and researchers in this area have linked a sense of autonomy in students with the realisation of student goals (Skinner \& Belmont, 1993). Assor, Kaplan, and Roth (2002) found that fostering relevance was particularly important in influencing students' attitudes to and engagement in learning. Clearly then, when learning has personal relevance for students and when they have greater autonomy in directing the learning process, they are much more likely to meaningfully engage in learning and to reach deeper levels of understanding.

Obstacles and supports to the development of digital information literacy revolve around factors that foster or inhibit quality engagement with information and technologies. Identifying these is an important first step in developing programmes that will reduce the inequities in opportunity to fully partake in social and work activities and life long learning.

There were two specific research questions to be addressed in this study:

When staff or students in higher education seek to develop or up-grade their digital information literacy skills:

- What obstacles to learning do they face?

- What aspects of the learning process or environment support their learning?

\section{Methodology}

A case study method was used to interpret, collate and present the findings (Halonen, 2008). This approach was chosen to enable the researchers to support the participants to collaboratively engage in activities that would progressively improve their digital information literacy through selfmonitoring and responding to outcomes (Coglan \& Brannick, 2002; Riel, 2007). Multiple methods were used to collect data to enable a triangulated exploration of the research question (Mertens, 1998). A multi-strategy approach brought together qualitative and quantitative aspects, enabling a fuller analysis and interpretation of the data (Bryman \& Bell, 2007). The methods included practical workshops, researcher observations and notes, focus group interviews, an email forum, reflections (in the form of web log or hard copy journal entries), action-learning spirals, and institutional and individual case studies. In addition, pre- and post-surveys were used to collect additional comments on participants' digital experiences.

Posters on noticeboards were used to recruit interested participants. Participants were invited to work on specific digital information issues they wanted to change for study, work, or personal reasons, and to do this within a group environment at their institution. 
Jeffrey, Hegarty, Kelly, Penman, Coburn, \& McDonald

\section{Sample}

Four groups of participants were involved, one from each of the four institutions (two polytechnics and two universities). Four sites were used to increase the robustness of the findings. A total of 42 participants, comprising academic staff, general staff, and students were engaged in face-toface workshops across the institutions. Thirty-one were female and eleven male. Nine participants were under 30, ten between 31 and 45, 20 were between 46 and 59 and 3 were over 60 . Most of the group were of European extraction with four Polynesian and three Asian participants.

\section{Practical workshops}

The participants attended workshops at their particular institution over a period of 10 weeks where they were encouraged to set their own goals. The role of the workshop facilitator was to guide the process; participants were expected to be self-directed and, where possible, to assist each other either by direct teaching or sharing what they had discovered.

Workshops followed the same pattern at each institution. The sessions began with participants sharing what they had done over the previous week. This was followed by a discussion on a topic of interest raised by the participants and then collaborative or individual work on their projects. The facilitators encouraged collaboration in the workshops and hoped that participants would communicate and interact outside the workshops as well, which many did. A range of tools and strategies were introduced to participants to assist them to access, interpret, and create digital information appropriate to their context, for example, Web 2.0 tools such as RSS feeds, Online Information Literacy (OIL) modules (http://oil.otago.ac.nz), wikis, blogs, social bookmarking, image and video sharing, and a variety of digital resources and software, many of which were requested by the participants themselves. The workshop facilitators concentrated on responding to the developing aspects of digital information literacy that affected the personal learning environments of the project participants.

An action research cycle approach was used that involved participants bringing ill-structured problems to the workshops and working on them in a scaffolded and semi-structured environment. In broad terms this involved setting one or more technology-related goals, searching for possible solutions and critically evaluating those solutions, and determining what new action to take. This progress was documented diagrammatically in action-research spirals. In all cases they were guided to view their participation in the project from an action research perspective. Therefore, the activities in the workshops depended on the direction in which participants wished to go and their individual interests and needs.

Participants were encouraged to use the Three Step Reflective Framework (Hegarty, 2007) to reflect on their progress and as material for their action-research spiral (Coleman \& Lumby, 2009), which was used to capture their action research cycles. Individual goals were set, plans were made, and action was taken. Their progress was self-evaluated. Subsequent steps were then planned on the basis of the evaluation and the cycle began again. For example, a participant whose pseudonym was Valerie went through three action-research cycles which she captured in action-research spiral (see Figure 1). Several steps are evident: 1) Description of the issue, goal and potential solutions; 2-3) Action; 4) Monitoring - reflection, learning, new planning; and 5) Evaluation which leads to the next cycle. 


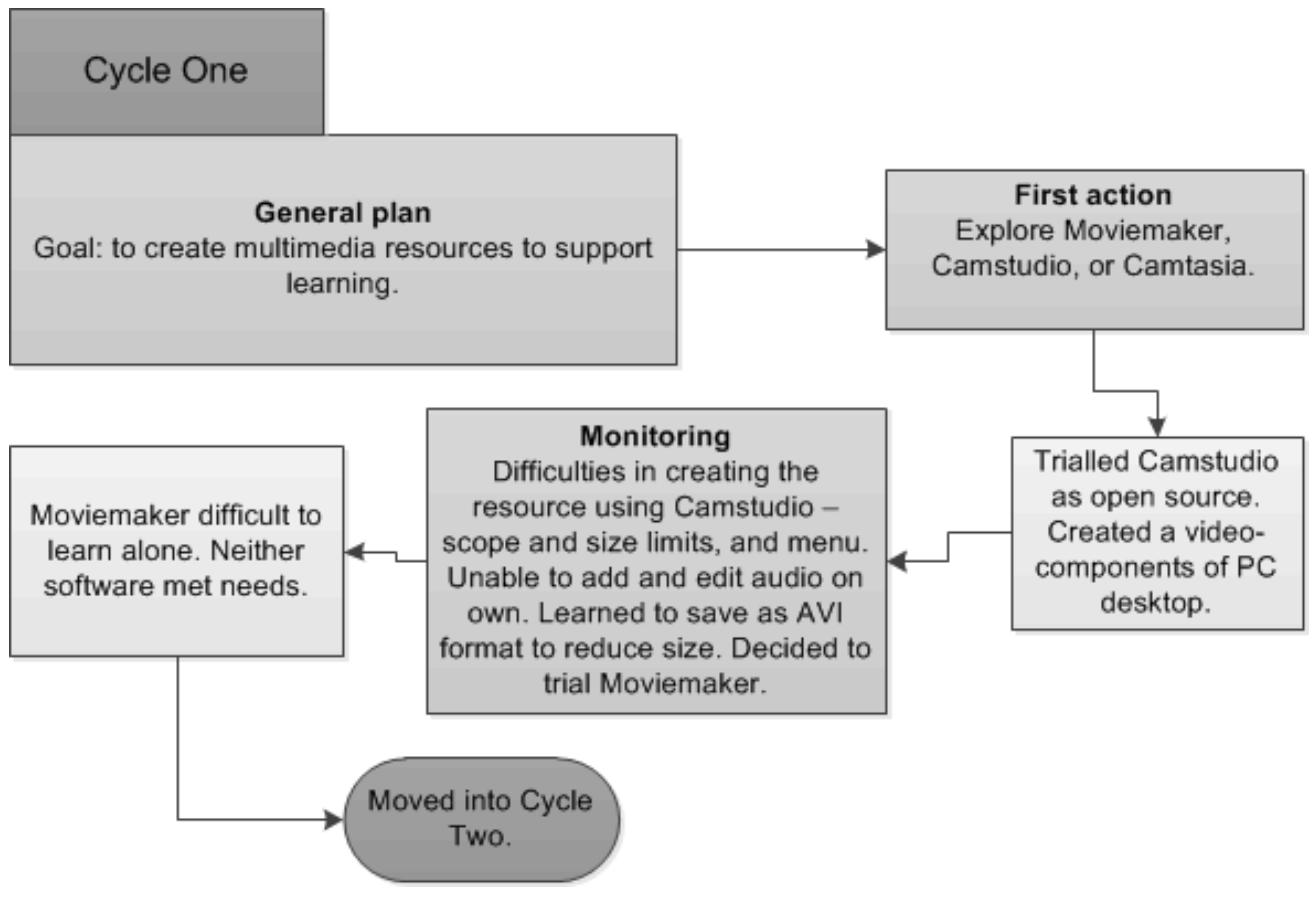

Figure 1: Cycle 1 of Valerie's action-research spiral

Facilitators recorded their own observations of the workshop interactions and progress of the participants, and these contributed to the qualitative data collected for thematic analysis.

Finally, at the end of the ten workshops participants took part in a one to two-hour focus group with members from their workshop. The focus group was audio recorded and this was transcribed.

The open-ended nature of these forms of data added richness to the data obtained from the surveys and the perspectives of the respondents were able to be captured in addition to that of the researchers. The methods used to collect data provided a multifaceted record of the processes and journey undertaken by the participants and formed a case study for each institution (see Figure 2). Additionally, the methods provided a thick description of the data and a level of specificity that would not otherwise be possible. In reporting the results pseudonyms have been used rather than the actual names of the participants. 


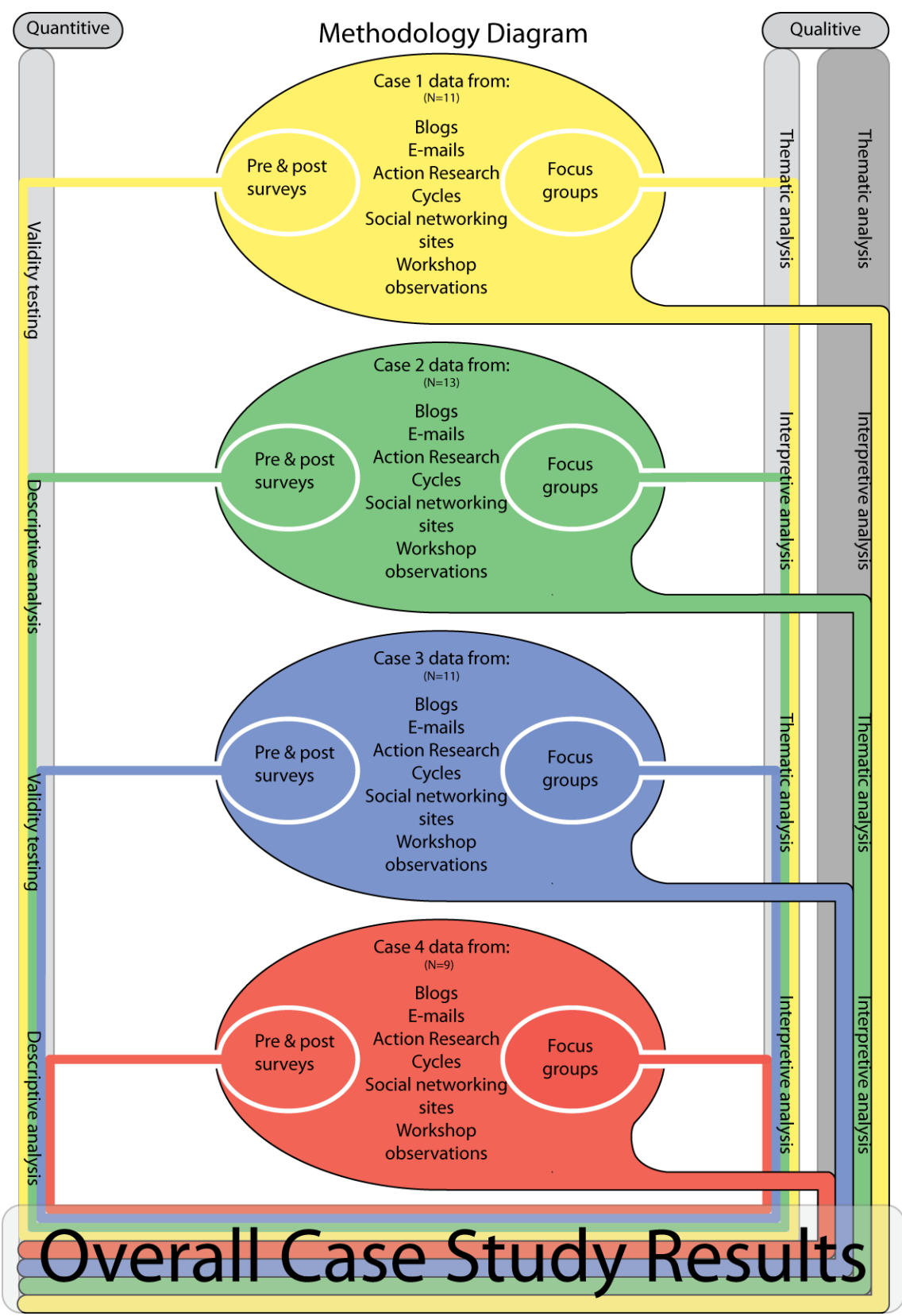

Figure 2: Methodology diagram illustrating approach used to collect data.

Data Analysis. Content analysis of the data was used as this is a systematic, reliable procedure that can reduce a large amount of text to a smaller number of categories (Krippendorff, 1980). The diverse sources of information allowed not only triangulation to test concurrence but also provided greater assurances that the researchers had understood the messages being conveyed by the respondents.

Observation notes, verbal reports, focus group transcriptions, and all the participants' textual data were compiled. One researcher from each institution initially reviewed the material from his or her own institution looking for obstacles to learning and aspects that supported learning. These two categories were subjected to further analysis in which emergent coding was used. Here the data was reviewed and themes were allowed to emerge from the data (Haney, Russell, Gulek, \& Fierros, 1998). Voices that contradicted the majority voice were sought to ensure inclusiveness. 
Two researchers that had not been involved in the first analysis reviewed all of the analyses. They met several times to discuss and check the category themes for consistency against specific examples from the data. Through this process they developed an agreed set of categories to capture the major themes in a relatively parsimonious manner. Data analysis and interpretation occurred through the process of examining themes and constructing categories to collate the data as the recurring patterns (or regularities) became the categories into which the data was eventually sorted (Merriam, 1998).

The quality of the study was measured from how it ensured credibility (internal validity) and transferability (external validity). Credibility was enabled through collecting material until all anticipated sources were retrieved and by using multiple methods of data collection and analysis for triangulation. Transferability was reflected in the use of thick description, which provided sufficient information for others to judge the relevance of the findings for their own context (Mertens, 1998).

\section{Results and Discussion}

Seven major themes emerged from the analysis related to obstacles and success. These include collaboration, access, confidence and self efficacy, time and permission to play, openness and learning from play, changing their approach to learning, and personal growth.

\section{Collaboration}

The case for improved learning from collaboration is well established in the literature (see, for example, Gokhale, 1995; A. Jones, Scanlon, \& Blake, 2000) and for improved motivation (Moller, Huett, Holder, \& Young, 2005). Within the institutional groups, conditions for collaboration were integrated into the research design. Collaboration was encouraged by the semistructured and facilitated nature of the workshops, the ill-structured problems each participant needed to solve and the forms of interaction used with participants (blogs, email group and focus groups). Therefore, interaction between participants was anticipated as they were encouraged to work together to solve their digital information issues.

\section{Resistance to Group Learning}

The researchers running the workshops determined early that their role would be facilitators rather than teachers to promote collaborative learning within the groups. Initially, some participants struggled with this concept. Rita said in the focus group, "I had the expectation that you [the researcher], were the expert [and teacher] and I actually found that quite hard and thought after two weeks, 'I have had enough of this'! I like to go in and get maximum input so it was actually quite a switch psychologically for me to say this is a different way of learning and now it feels, on reflection, like a much better way of learning than just having one person having the knowledge" (Rita, focus group). Comparing this to what Rita had said in an earlier blog suggests how far she came in changing her attitude to collaborative learning. Previously, she stated, "I am doing another course and was reflecting on how I am learning all that new information. There are two key things to my learning which parallel this experience on DIL. The need to have an "expert' to answer the hard questions. Other classmates are useful to embellish and explain but I think there is always a role for a "teacher" (Rita, blog post).

Despite the initial reluctance to engage collaboratively, when faced with unfamiliar learning tasks and a relatively unstructured learning environment in which the 'teacher' took a less central mentoring role, participants in the study progressively built small communities of learning that evolved into cohesive, supportive networks, a finding that echoes Wilson et al. (2004). Participants turned to each other for assistance and discovered that their fellow group members collec- 
tively were able and willing to supply help and support, an outcome predicted by the work of Horsburgh, Lamdin and Williamson (2001) who found students became much more positive about collaborative learning once they had experienced the benefits. Wilson et al. (2004) refers to this as mutual appropriation, in which participants adopt the roles of both teachers and learners. Helen echoes this sentiment in a blog post.

"What did I learn? Well, other than del/icio/us and some other websites - the most important bit was to learn to give it a go, and to remember how much fun it is to learn with a group of people doing their own thing, but helping each other. I was exhilarated by the end of the session. So next time I will go with confidence that I will enjoy myself, and get something out of it, no matter where I start from." (Helen, blog post)

Even so, group learning is usually less favoured by students who feel that group work dissipates their own effort and encourages social loafing (Hunt, Eagle, \& Kitchen, 2004). Initially, this attitude was apparent in the project. For example, one of the participants commented:

"It was mentioned by group members, who are also employed as teachers and managers, that students baulked at getting in to groups for learning and I would identify with that because I hate it. As soon as a lecturer says get into groups, I think, 'god I wish I hadn't come today." (Vera, focus group)

At the end of the project Stewart explained how interaction in the group had helped him to learn. For example:

“... one particular person I did find particularly helpful within the environment was someone that showed me not to be fearful, helped me to understand that it is okay to be a bit sort of left footed and stuff like that .... I found that a really stimulating learning environment because what Lesley started with was a question and consequently everybody fed in to the question so you could develop your own understanding as it went along." (Stewart, focus group)

The networks formed by the participants appear to have helped to create a safe, supportive learning environment in which they felt they could push boundaries and take learning risks. Wilson et al. (2004) also argued that such environments encourage members to risk making mistakes, promote a shared responsibility, and distribute control. The success of the groups may also, in part, be attributed to the willingness of the participants to undertake the various social functions, such as encouraging, described by Jacques (1991) as being essential to effective group functioning.

Although Vera was anti-group learning at first, she eventually found the safe, supportive collaborative approach adopted by the group enabled her to push boundaries while knowing she had a safety net. She expressed this by saying, "One of the best things that's ever happened to me - this group" (Vera, workshop notes), and "Group learning is a brilliant format. It reminds me of the movies, as the American marines say... no one ever gets left behind" (Vera, blog post). She felt that the approachability and support of all the group members created "a safe environment" for her to be able to say "I don't understand". Someone was "always available to help and learning blossomed" (Vera, blog posts).

The groups built a sense of identity using shared personal experiences (for example, feelings of frustration) and rituals. One example was the catch phrase "There's always Friday" (the day the group met) coined by Vera and adopted by the group. Problems and frustrations, which Vera said she experienced between meetings, were tempered when she told herself that even if she could not solve a problem at the time, on Friday someone in the group would be able to help. Community identity, a characteristic of learning communities, emerges from a shared history and the intensity of the interaction (Anderson, 2009; Wilson et al, 2004). 


\section{Shared Experiences and Diverse Skills}

The diverse nature of the groups, which included ages from 20 s to over 60 , roles from highly proficient technologists to novices, and a mix of gender and ethnicity, brought a blend of experience, skills, and perspectives that provided rich resources for each group. As a result, learning became a shared experience. This experience included not only the acquisition of new information but also successes and disappointments. Particularly liberating was the realization that most people shared the same fears and frustrations, a point emphasized by Vera, "I listened to them all \& I was last to speak. When I proclaimed my doubts especially re-jargon comprehension the room was abuzz with agreement and hey I was not alone. I started to relax and feel more comfortable" (blog post).

While diversity also brings challenges to the cohesion of a group, in a safe, supportive environment it presents opportunities for multiple perspectives and new ways of learning (Wilson et al., 2004). Participants became aware that others in the group, who may have had fewer digital information skills, were still able to show alternative models of learning or approaches to problem solving. In this environment, group members shared ideas and skills willingly. Katie found "... the discussion groups [were] invaluable to see how others were utilising different modes in their teaching. Where they had accessed info etc" (post-survey). In a focus group, she said, "I found it was useful to look at what other people were doing - starting out there on their blog it was really good just to be able to see what other people had done, it was like, is that a good model or not?" This sentiment was also expressed by Valerie who also found sharing with other participants motivating, and wrote, "the group was diverse and that is interesting to see other people learning" and "it really gave me a sense of community, but also that other people were interested in the learning because that is a motivator on a different level.... Everybody doing something different added to my knowledge" (Valerie, blog post).

Helen described how she benefited from the learning and exploring of others in the group.

"I try to keep up with everyone else's blogs once a week or so - which has been a great way of feeling still involved, even if they're working on something that I don't intend to follow up. And I realise I've learnt so much about web tools and ways of working that I never would have made time to find out for myself. So my potential 'tool box ' has gotten MUCH larger - It's like everyone else has been buying fancy kitchen equipment for my cupboard and showing/telling me what it's for - I may not want to use it just yet, but if I ever get around to doing a really fancy dinner...." (Helen, blog post).

Vera had an interesting explanation for the success of the groups, "Everybody gets a thrill from each others' achievements" (Vera, blog post).

Even though learning from the collaborative environment was expected, the level of emotional bonding within the groups was surprising. By the end of ten weeks, they had become very cohesive. As one participant said, " $100 \%$ easier and enjoyable to learn with a group who become friends and mentors" (Vera, blog). Although one person in the study made a negative comment about the collaborative format because he felt it was inefficient, most people expressed satisfaction with the method. Katie's comments capture a recurring sentiment expressed towards the end of the project, "I have enjoyed learning in a community of practice" (Katie, focus group). She also stated, "The thing about this particular project that's been useful for me, we have come together as a community of learners, a community of practice and I'll miss it when its not here" (Katie, post-survey).

\section{Incidental Learning}

One of the advantages of collaborative learning, identified during this study, was the amount of incidental learning that occurred. Participants often did not know what to ask because they did not 
know what existed, but ideas and tools mentioned or demonstrated by others in the group prompted unexpected learning. For example:

"There is a lot of learning by accident.... I mean I learnt a lot of stuff that I wouldn't have because I didn't even know it was actually out there to learn and even if I had known, I might not have - if I said oh no, I just want to learn this, and just be very blinkered but because other people were learning it and they were enthusiastic so it wasn't so much a matter of going to someone and saying can you actually help with this, it was actually peering over the shoulder and going "what are you doing?" So I wouldn't have thought to go and have a look at Mahara and I might never use Mahara for any portfolio but now I know what it is, and now I can make a decision about whether to use it or not and that was something that I wouldn't have ever asked anybody how to learn." (Helen, focus group)

Overall, one of the benefits for participants in the research project occurred through the opportunity to learn collaboratively in unique groups at each institution. The collaborative process revealed the importance of a particular disposition underpinning digital information literacy, namely sharing. A willingness to share information was found in all the groups and is associated with advanced skills in managing digital information.

The effectiveness of learning in a collaborative environment has support in the literature. J. S. Brown (2000) advocates the importance of "immersion in a community of practice" for successful digital learning and enculturation in web environments (p. 15). Hegarty et al. (2005, p. 2) found that being part of a situated team where a "metacognitive learning process with both training and scholarly activity" is undertaken with others, promotes a community of practice.

Collectively, many of the themes identified in this study provide support for the work of Wilson et al. (2004) and Anderson (2009) as groups in the study progressively assumed the characteristics of learning communities. They demonstrated a shared goal (improving digital information skills), credited a safe, respectful environment and a large measure of trust that was important to their willingness to take learning risks. They proclaimed collaborative learning to be powerful and found that both teaching others and learning from them to be immensely satisfying.

\section{Access}

A number of issues related to access were very similar across the four groups, including physical access, familiarity with tools and strategies, Internet terminology, and risk.

Discussion on access to technology has largely focused on the 'digital divide' issue (Castells, 2001). A more subtle version of this problem arose in this study when participants found differences in access capability between home, workplaces, and the workshops. Having learned about a tool or useful website, participants experienced frustration when they were not able to practice and apply their new skills outside of the workshops because the equipment at home or in their

office had much lower capability. Comments such as the following were typical:

"During the week I've had a look at two social networking Web sites, Del.icio.us and Twitter. I couldn't get very far with them on campus - the firewall blocks adding the Del.icio.us buttons, and stops the streamed video on how Twitter works. Must have a look at home." (Tammy, blog post)

Consequently when participants were exposed to digital tools and resources during the research and found their progress slowed by access barriers the frustration they experienced was sometimes demotivating, leaving them feeling like 'outsiders' (Maria, blog post). 


\section{Familiarity with How Things Work}

The literature on student engagement suggests that an important aspect of fostering engagement lies in making learners feel they are a part of the discipline area (see, for example, Krause, Hartley, James, \& McInnis, 2005; Parappilly, Quinton, \& Andersson, 2009). In addition to feeling excluded because of physical barriers preventing access to tools, participants encountered other obstacles due to their inexperience in the open web environment. They reported that a lack of familiarity with the breadth of digital tools, the terminology, and the common procedures used limited their ability to identify solutions and to navigate the digital environment. All participants were either tertiary staff or students and used a computer for their work or study. Generally, they indicated they were comfortable with the tools they used regularly, such as search engines and library databases. However, when stepping outside this zone of familiarity they encountered further barriers that hampered their progress and motivation. Participants often did not know what sorts of tools were available, where to locate them, or which sites were most suitable for the purpose for which they were needed. For example, most participants were not familiar with photo sharing, bookmark sharing, or document sharing sites. Although, they knew about Youtube, they were not aware there were other video-sharing sites.

A substantial part of the problem arose because participants did not understand the processes involved in using the sites. The facility-sharing websites, for example, were not seen as userfriendly to the uninitiated (for example, Blip.tv, Youtube, Bloglines, Wikispaces, Google documents, Slideshare, and Flickr.com) because as new users they did not understand the security measures employed by the sites. These measures include registration, setting up a profile, verification emails, activating the accounts, and antirobot/spam devices (such as verifying security letters when submitting comments on a blog). A common occurrence for many participants in the workshops was to try to $\log$ onto to a site, only to be repeatedly told the username or password was invalid. None of the error messages mentioned that it was necessary to register before access was given through logging in. This misunderstanding was repeated a number of times before people began to remember to register first. Several participants in the workshops related stories of their adolescent children making the same mistake. Other features that made websites unfriendly to users in the study were inconsistent standards and protocols, which required re-learning the system for each new website. For example, having to have different types of username and password for different sites caused some confusion for participants. These small problems and inconsistencies seemed to cause the greatest discouragement for participants.

In addition to Internet barriers, participants themselves often created access problems. For example, many participants who were new to social networking Internet sites, such as Flickr.com (image-sharing), Delicious.com (social book-marking), Animoto.com (video creation), and various blog sites, encountered difficulties when they were unable to login when returning to the sites. The primary reason for the difficulty in accessing the sites was participants' failure to remember their login details - username and password. In some cases, once they were shown how to request login details from the site, they gained access; however, in some cases they had to set up new accounts. Also, participants often did not know how to manage multiple login details, and as one participant (Carol) said in a workshop, "I have too many and I forget them." Carol was assisted by a facilitator to organise her logins and web addresses using iGoogle.

\section{Terminology}

As well as actual access to various sites, terminology used on the Internet was a common problem. The jargon associated with the online environment led one participant to say, "Being exposed to a lot of unfamiliar words/concepts, I felt like I was in a foreign country where I could not speak the language, which was initially frustrating and discouraging" (Maria, blog post). While the meaning of a single word was easily checked, the prevalence of jargon lengthened the 
time needed to complete even simple tasks. Many found that they needed to become comfortable with the language of the Internet before they could progress their skills and communicate with others in this environment. For example, some terms that participants encountered early on related to tools and online strategies, and included RSS feeds, wikis, Web 2.0, social networking, social bookmarking, gadgets, widgets, download, upload, wav, mp3, open source, names of software, and names of social networking sites.

Persistence with digital language skills brought several benefits. Participants found that knowing the jargon was very important when they called on family, colleagues, or professionals for help.

Not only could they ask for the appropriate help, but they could also understand the solutions better, and they became more willing to try another approach when one did not work (focus groups). A belief emerged in all the groups that being able to understand the terminology associated with computers and the Internet would enable better communication with others who were very competent digital users. For example, one participant stated in a focus group discussion, "There's a culture, (dunno if it's a geek culture or what) and those who can belong are digitally information literate, and I'm starting to feel as if I belong because I can communicate with my son on similar terms" (Katie, focus group). Another wrote, "The next time I read PC World, I felt like I knew what it was saying. That was because again it's the terminology and the language that makes a big difference" (Bernice, blog post). It was only through the workshops that participants became more aware of the digital possibilities and become acculturated to the Internet environment. Their horizons broadened and they often found more creative solutions to their initial problems or the learning objectives they brought to the workshops. However, without structured support it may be that significant groups of individuals may find the Internet an impenetrable barrier.

\section{Risk}

Access was sometimes self-limited by participants concerned about their personal information being too readily available on the Internet. In the workshops, researchers observed that the participants differed markedly in their confidence levels with regard to digital identities and privacy of information, which they associated with risk. It is well established that our decision-making processes are influenced not only by the actual level of risk we face, but also by our perception of risk. Individuals often overestimate risks for things that differ from their normal situation, particularly if it relates to being under public scrutiny (Rauhofer, 2008). Exposure on the Internet, particularly the construction of a digital identity, falls into this category.

Participants in the study initially struggled with the openness of web-mounted aspects of the project, such as blogs. One participant commented about what she found on a family member's Facebook, for instance, "All these photos are just sitting there and I thought he was sharing just with us and suddenly he's sharing them with the whole world I think Oh I have to get used to this whole new way of thinking.... The openness" (Liza, focus group). However, when supported in the experimenting phase, participants became increasingly comfortable with sharing material in the open domain. Blogging especially was noted as a form of communication many had not tried before; however, with the encouragement and discussion at the workshops participants became more confident and more willing to share their progress and thoughts online. It would appear that familiarity gave confidence, as did a growing knowledge about the possible risks and strategies for improving security when using Web 2.0 tools.

\section{Confidence and Self-efficacy}

While some participants had high levels of digital information skills and self-efficacy, there were others at the other end of the spectrum who were technophobic, particularly at the beginning of the project. These attitudes and beliefs emerged in their writing, their interactions in the workshops, and in the pre-survey. Prior to this project, these beliefs had prevented them from being 
willing to take risks or explore unknown digital territory. For example, when Carol engaged in a process of learning a new tool (blogs) she felt it confirmed some of her beliefs about herself, that is, "web stuff is not me" "I'm a technophobe" and this was reinforced when she had difficulty creating a new blog post (Carol, blog post). She felt the process was frustrating and made her feel stupid. In her blog post, Carol expressed her concerns, for example:

"I feel that I'd not want to have a blog, being such an introvert and a bit of a wimp. The out-there-ness of it is interesting. I am not confident about even commenting on someone's blog. I don't know how to create a blog, but the question is, do I want one?" (Carol, blog post)

Carol also described in her blog prior poor experiences with mastering technology and found that some of these experiences were at times repeated in the workshops. As time went by, Carol reflected on her experiences in the workshop and felt she was making progress, and although at times she still felt frustrated and discouraged, she said she was gaining motivation to keep persisting. Carol's low level of confidence with technology created a barrier to her use of the tools, as did her unwillingness to take risks ("trying things out and not worrying if they don't work the first time") (Carol, blog post). Low self-efficacy in technology is implied by her statement "I'm a slow learner where technology is concerned" (Carol, blog post).

For some participants, anxiety and low self-efficacy went beyond psychological symptoms. One participant reported experiencing distressing physical symptoms and connected them with her feeling of inadequacy in using computers. Stewart, a participant in her group, related to her experience by saying, "I too suffered those sort of physiological reactions with the [technological] environment that I was going into and consequently I just didn't go into it, I only went into it when I had to (Stewart, focus group).

A noticeable change occurred in the participants' attitudes and beliefs about their abilities as they experienced success. Carol, for example, credited the workshops for her successful outcome with Skype and at the end of the project she said she was "more prepared to try things" (Carol, focus group). Bernice was also more positive by the end of the project. For example:

"Definitely feel more knowledgeable, confident. I don't care if I don't know now 'cos I can go out and find out. That's my attitude, whereas before I was a bit hesitant." (Bernice, focus group)

All of those who had indicated they had very low regard for their ability to gain new digital skills and knowledge in the pre-survey and the early workshops grew in confidence and self-belief by the end of the project. Those who had experienced physical symptoms of anxiety when faced with a digital task found, to their amazement and relief, their feelings of anxiety disappeared during the project. These growing levels of confidence were evident in their writing, their interactions in the workshops, focus groups and in the DIL scores obtained from the exit survey.

\section{Time and Permission to Play}

Finding time and having permission to play came through strongly in the focus groups from two institutions. Most felt they did not have enough time yet recognised that nurturing new skills took time. Balancing the importance of developing these skills against the urgent demands of work or home was on ongoing issue for most people. Participants felt that having time in the workshops gave them the opportunity to play with new tools and work towards achieving their goals for digital information literacy. Attendance at the workshops gave them a structured time when they were allowed to explore and try out new tools and strategies (play). Thomas explained the concept of time in a focus group: 
"Because like ... seeds, when a seed falls to the ground you've got to give it time. I think that's something like myself. I've got to have time to process that, but also to allow it to grow there, so because I've injected an amount of time here I'm not going to let it be wasted because that information and that knowledge base that I've gained is going to be used to the advantage of the students here and also the staff. So, yes, it's increased my confidence, also it has allowed me to know that things start from a seed and then they start to grow so thank you for that." (Thomas, focus group)

Stewart's comment was representative of the way in which participants felt time was legitimized by the project, "I think one of the biggest pluses for me in being part of the group was that I committed myself to a two hour period where I was almost forcing myself to be involved in something when I might [otherwise have found] something else to do" (focus group). However, justifying the time needed for practice away from the workshops was harder, for some, as stated by Mary, "Time was my major issue. I did not have enough time away from the [project] to put things into practice" (post-survey). Conversely, Sarah recognized the process was time consuming but felt it was justified, "I do not see it as a waste of time because it is my way of learning and it has had academic outcomes already e.g., I have had one conference paper and a book chapter accepted within the space of 9 months, based on my online experiences and learning" (Sarah, blog post).

Participants certainly realized the value of dedicated time to develop their digital information skills. Nonetheless, many participants said during the workshops that they had to overcome feelings of guilt when using the technologies. Exploration of web tools was something they thought should not be done in work time, or it was something that a busy person could not afford to do. One person had to be persuaded that she did not need to come to work at weekends in order to feel comfortable about actively developing her digital information literacy during regular work hours (when the workshops were held). Other peoples' perception of what constituted work and play also had an effect on participants. For example, Sarah said in the focus group:

"There's so much blurring of the lines between work and the computer, blurring between what is work and what is so called play. ... and it really came to the crunch the other day. My husband came home and said what are you doing, why are you spending half the day on your blog writing something - he sees that as play, and Second Life is even worse of course. He sees it as play whereas it is not, it's work."

It was evident during the research project that without this play component people were not really able to see new possibilities or gain the confidence they needed to try new tools and methods. This became apparent when participants mentioned during workshop sessions and in the focus group at the end of the project that just following instructions and going down someone else's pre-determined path for learning had often failed them in the past. In contrast, during the research project use was made of an action research spiral for activating and monitoring progress and this enabled a dynamic goal-setting process, providing participants with autonomy over their learning. Autonomy over learning and personal relevance has been strongly linked with the level and quality of learner engagement (Assor et al., 2002; Skinner \& Belmont, 1993). Participants with specific goals to which they rigidly adhered were in the minority because participation in play during the workshop sessions revealed previously unknown gaps in skills and knowledge and opened up new possibilities for most.

\section{Evaluating Alternatives and Adjusting Goals}

Some participants admitted to thinking they knew more than they did at the start of the project. This group often showed surprise at the number and type of tools that were freely or easily available to support their study or work that they had not previously known about. For example, open 
source software and social networking tools such as social bookmarking (Delicious.com) and slide and audio sharing sites (Slideshare.com, Myplick.com, Blip.tv, Internet Archive). Participants who experienced this sudden awareness of what they did not know frequently adjusted their goals as a result of the new information. It was noted in the workshops that participants often deliberately chose to put aside their initial plans in order to be able to explore the range of that which others in the group were using or were learning to use. These participants chose to be exposed to the range of tools. Usually they took enough time to become familiar with the tools; they made notes or in some way recorded what they wanted to remember about the tools so that they could come back at a later point after the project. As such they were evaluating the tool against their own criteria, which was usually related to the tools potential value in supporting their ongoing study or work.

Some participants revealed that they scored themselves lower in some aspects of digital information literacy at the end of project survey (compared to the pre-survey) after becoming more aware of how much they did not know. For example, one participant approached a facilitator, mid project, with concern about the extent to which she had initially overrated herself, through what she now saw to be ignorance regarding she knew about digital tools.

\section{Openness and Learning from Play}

Dewey (1933) promoted the value of experiential learning. A number of writers have noted how this experience often takes the form of playful experimentation or bricolage in the online environment (see, for example, C. Brown et al., 2003; Harel-Caperton, 2005; Tuckle, 1995). The notion of learning from play was often raised by participants during the project. Participants recognised that this was an effective approach often used by young people. Playing was an opportunity to explore with an open mind to see what was there. It was about being open to new opportunities. Helen explained it like this, "I think this approach of playing around with it being completely open and not expecting anything, like this, this and this for the information at the end is what made this group very successful. Everyone was just curious and got on from seeing and doing what others were doing so that is the best frame of mind for learning" (Helen, focus group). Fiona thought this approach was very useful in a very new learning context, "It's interesting isn't it, before you know stuff, it is hard to set objectives because you don't know what you need to know but as you get in to it, you start to get a clearer picture of what it is you need to know or should know" (Fiona, focus group).

The idea of being open to new opportunities was endorsed by Brenda who said, “... having the attitude that I am here to learn something. I am not exactly sure what, at least that was my approach and the readiness of taking whatever comes up. I will have a look to see whether I can use it or whether it is of interest to me. I think that was what made this successful for me at least" (Brenda, focus group). Katie likened the experience to children getting an Advent Calendar. She wrote:

"I used the metaphor of a children's advent calendar for my learning over the time of the project; opening a series of exciting doors to reveal what lay behind. I feel like I have been playing with many tools and many ideas for their use. Each new door led me to another set of ideas that I could put into practice. I felt that during the project I needed to learn everything that was on offer. Now the project is over it will be time to consolidate and close some of the loops on the active projects I have started on." (Katie, blog post)

The ability to understand play as a useful learning strategy was influential in helping participants to build their confidence to tackle new aspects of digital information and was a skill they took with them when the project finished. Having the time and support to play with a range of tools 
Jeffrey, Hegarty, Kelly, Penman, Coburn, \& McDonald

over the duration of the research enhanced participants' ability to access a broader range of digital tools and information and shifted their attitudes about the possibilities for their study and work.

\section{Changing the Way They Learn}

Most participants found that their development in digital information literacy was matched with a change in their learning behaviour. An interesting aspect of this change was a growing selfawareness of how they approached learning and what worked for them. These changes manifested themselves in four ways. They came to recognise that their old methods of learning were not suited to learning new technology and, accordingly, made shifts in their approaches to learning. Secondly, they found that as their confidence grew, their attitudes changed from fearing the technology to feeling that they could 'give it a go' when faced with new problems. In other words, they increased their self-efficacy with digital information. Thirdly, they realised that learning to use new digital tools in this project was different from normal classroom learning in which the focus is often 'learning about'. Learning new skills involved practising the skills outside the classroom and was, therefore, much more time intensive for participants. Understanding the importance of practice and being willing to commit time to achieving desired levels of skills was also a change for some people. Finally, partly due to the nature of the workshops and the use of reflective journals, many participants recorded personal growth and increasing independence as learners.

The adoption of new strategies or approaches to digital learning was frequently commented upon. Rita puts it succinctly, "I need new ways of learning with this stuff, it's about process not outcome" (Rita, blog post). Stewart's comment in a focus group expands on this idea of process in learning, "So probably the life long learning for me has been the notion that change is inevitable and you have to lose something to actually gain something. A lot of the traditional methods that I have used with my education don't seem to apply that much with the new sort of speed of accessing and the Internet and stuff like that so I have had to change a bit about the way I think I learn, about the way I set goals and stuff like that" (Stewart, focus group).

One of the most common strategies was to "just do it!" according to Helen in a blog post, and work through problems if they arose. This approach had the advantage of increasing confidence when it was successful. However, participants found it was more time consuming. Bernice expressed the need for support, "I think my preferred learning style is to have exposure to something new - an idea or software - have a "hand-held" first experience, then play with it on my own, knowing that I can ask for help if I get stuck" (Bernice, blog post). Valerie also used the 'just do it!' strategy for learning, as indicated by, 'I just click here and what happens and oops that isn't what I wanted, so I do a lot of that and I find that quite helpful. You learn something every time you go around and around the menus" (Valerie, focus group). She mentioned that playing a lot on her own helped because it "gave me more confidence in actually using it and when I came to a problem, instead of just giving up I was trying to work through until I found the solutions" (Valerie, focus group). Valerie also acknowledged that she learned in a particular way, and said, "I wouldn't have necessarily given up [on the task], I probably would have put it away and not gone back to it in a big hurry".

Just having a go was a personal shift for Jesse who wrote on her blog, "I think the more you do just give it a go the more confident you become. I also think the support of others around you is really beneficial." In a post-survey response she wrote, "my confidence has increased as I have learnt the new technology", that "has made me keen to learn more to enhance my teaching practices" and "there is great excitement when I conquer something new" especially "if it is something I have heard others talking about or observed and wondered how they managed to do it" (Jesse, post-survey). 
In the exploratory learning environment of the project, participants often developed problem solving strategies that involved using the Internet. The statement by Valerie epitomised a frequent comment by others, "I would be more likely to explore online tools and see if they are an answer to my problems" (Valerie, post-survey). Similarly, Rita wrote, "... now if I wanted to find something out I would go to YouTube first to find out what to do, have a go, ask an expert to help and then I reckon I would have it sussed!" (blog post). Andrew also advocated using the Internet to find answers, "But I will tell you what, people who are working in isolation, you can just type a question in to Google. Google will find [an answer], you will be amazed, you will find hundreds of people who have worked on similar problems who have learnt all the tricks. So people have spent their time to doing this problem, we did this and this didn't work so we did this, and you will get the solution, that's what the net will do, if you have a problem then go to the Internet and there you will find a solution" (Andrew, focus group).

Faced with a learning environment that was unfamiliar to them, participants had to evaluate how they had worked in the past and make adjustments to the new context. Rita reflected on her own learning and found it allowed her to "identify obstacles within my own thinking that I wasn't aware of that have prevented me from learning in the past" (blog post). Helen, who was not a teacher, found, "Helping others is good fun and good for confidence levels - and I often learn more by helping" (blog post).

In the pre-survey, Fiona identified her preferred learning approach as being "given written guidelines, then working through them with someone on hand to help". She found that "I live with computer savvy people and it is a waste of time to employ trial and error when there is often a simple step I have overlooked" (Fiona, pre-survey). In an early blog she wrote, "I tend to have a lack of persistence in trying new technologies because I do not have endless amounts of time to use trial and error. I also manage to do something but then returning after a period of time I forget how to do it. I need the repetition to make it stick into long term memory" (Fiona, blog post). By her final blog, her view had changed, "However on reflection what I have gained is a change in attitude towards technology. I have observed other people's different approaches to learning new things and realized that my attitude is all I needed to change to be able to do anything I want in this area, and that is huge for me. I have relied in the past on others to tell me what to do technologically, instead of thinking it through for myself. It is not what I do in any other area of my life. I have been a little afraid to use trial-and-error learning as it seems often to be a waste of time when someone knows the answer. But from now on I will use tools such as Wikipedia and Google and even YouTube if it helps throw light on a puzzle" (Fiona, blog post).

Other participants also reported changes to their approaches to learning, for example, Bernice found that she had "to keep learning the lesson of patience with myself and my own ability to learn and then remember that other people have the same thing about having to process and learn" (focus group). For Rita it was about structuring her learning; she "wanted to know everything but learning needs to be in small chunks. Learning the basics first - not the fluffy stuff" (blog post). She also realized she needed to be discriminating, "Good to sift through all on offer and decide what I want to keep, whereas initially I felt I had to know it all... Have I learnt much? Yes, but I must admit it has taken longer than I had thought ... But I realised that it is all not as daunting as it was at the beginning (blog post). Using her new approaches she found that: "Learning is incremental but progress is getting made, don't feel I am on the outskirts of technology any more" (blog post).

Victoria found a slightly different approach worked for her, "I find I need to keep it simple - by using the reflective step in the process I can take more control of the process and am not frustrated by the problem" (post-survey). Brenda described her approach to learning digital skills by using an analogy to reading skills, "I sort of use the analogy around literacy, we all have word attack skills. If we don't know a word we can sound it out and do it phonetically in phonemes... 
and so I think that is the same with digital literacy skills, you can find your way around them, if you have got the word attack skills" (focus group).

A number of participants reflected on the impact of their new learning skills on their future behaviour as illustrated in the following quotes:

"Now, I'm to grow up with this learning. This way of learning will eventually be an everyday part of my life. I will use this technology as though I can't be without it. Much like checking my cell phone every morning to see if messages have been sent while I was asleep. My children and their children will grow up with this information capability and I need to grow with it, or get left in the dust like stale bread and stagnant water." (Bernard, blog post)

"I don't think digital literacy will ever stop - it will just get bigger and bigger. This programme has helped me be more proactive about things - actually look for stuff that I never thought was possible. I could actually go and look and see where to find it - it was just a matter of where I went and deep interactive learning - as a student I hate lecturing, just standing there saying "this is a piece of paper" read it or don't. Finding ideas and brainstorming. The Internet lets you do that to a wider community. You don't have to be stuck in the one classroom, these are the people you contribute with, but you can contribute with outside people as well, because the Internet has got a bit of everything that you want. It's creating your own package of what you want to do and finding the answers to be able to do it." (Naia, focus group)

Most participants commented during the project on the emotional ups and downs they experienced as they were learning, from highs to frustrations when things went wrong. Two of them explained these more fully. Jesse reported that her feelings about learning a new tool differed at each stage, and wrote,

"Usually at the beginning I was optimistic and felt reasonably confident. As I moved along feelings were mixed depending on how well it was going. The end usually brought huge satisfaction, pride and confidence" and "I felt [both] challenged and frustrated. When things went well I was very excited, if they went bad I felt very angry... usually blaming the computer or the program." (Jesse, action research spiral)

A participant from another institution made a similar reflection.

"I found it interesting that I still had a similar range of emotional responses to this issue feeling upset and embarrassed that I didn't have the software working properly (not very professional), then getting over that and actually enjoying at least some of the problem solving part, then frustration that I couldn't get it sorted - relief that I could get help, and finally pleased with myself that I got somewhere. Maybe I will just continue with that cycle whenever I learn something new." (Helen, blog post)

She went on to note, "Some degree of tenacity and self belief is required to lead to success" (Helen, blog post). As demonstrated, participants made very real changes to the way they approached new learning and exhibited a range of strategies and engagement in action learning.

\section{Personal Growth and Attitude Shifts}

Most participants saw their learning during this project as a form of personal growth in which they became more independent in their learning. Victoria explained "there's a kind of apprenticeship process that you go through when you learn something in the early stages, the middle and the last, and that is the process of becoming independent in a way" (focus group). Sandra saw it more organically, "The [project] provided a starting point. I came looking for a start point, so I will 
keep on using it and keep myself organised. I have continued to use it like this since we finished the [project]" (focus group).

This personal growth was important for participants in developing autonomy in using digital tools for information. Almost everyone commented that they had experienced a shift in attitude. Many started from a position of feeling negative about technology: some were so fearful they had physiological reactions when confronted with it, others were proud of their technophobia. In time they came to view it as essential to being literate in the 21 st century and even a source of enjoyment. Stewart, who initially experienced physical symptoms of distress when confronted with having to use technology, discovered the many resources and tools available and became excited and interested to find out more instead of limiting himself by avoiding them. Mary described a typical fear that many participants had of being afraid of touching the technology and breaking it or causing irreversible damage; she went on to say what happened when this fear was overcome, "you don't look at it and think you can break it or break the world now, I am much more able to try something before I run for help. In other words, whereas initially I just looked at anything new and yelled 'help ', now I don't ask for help until I know I have tried all manner of things and I am really, really stuck and that 's a huge growth thing for me" (Mary, focus group).

Avoidance behaviour was also typical of Fiona as evidenced by her comment in the post-survey, "the skills I have mastered will be of life long importance to me, but more important than the skills I have learned is the attitude change I have experienced. Where once I would have shunned tools because I thought that using them was going to be too difficult, now I will give it a go... I feel I have removed a barrier in my mind about learning these tools. I now know there are a number of ways to tackle the learning or sourcing of information and I am less likely to give up if I do not get a solution immediately". Such attitudinal shifts impact not only on the immediate learning task, but auger well for future learning.

\section{Conclusion}

Advanced digital information skills are necessary for teachers and students if they are to participate in higher education and lifelong learning. Obstacles to developing these skills can be internal, such as attitudes, or external, such as access to opportunities. Self-limiting barriers relating to self-efficacy, confidence, and attitudes will change when the learning context meets a number of conditions. The most frequently mentioned of these was a safe, collaborative learning environment where students felt they were part of a supportive community. In this context they were free to take risks with their learning, were willing to ask for help, and felt confident they would be supported through difficult stages. They drew encouragement from realizing that others faced the same issues as themselves and that they were not 'techno-idiots'.

Structured time for 'play' seemed to be important for adults when learning new digital skills. Bricolage has been intuitively adopted as the means for mastering Internet technology, but in a work environment such behavior has overtones of frivolity, and some of the adults on the project had to overcome feelings of guilt about engaging in play-learning. The weekly workshops had the effect of giving them 'permission' to play.

The collaborative nature of the project had several benefits. The diversity of the groups ensured that problems were viewed from multiple perspectives and consequently many interesting and novels solutions were found. Through this process, participants modeled for each other alternative approaches to learning, increasing everyone's repertoire of strategies. This aspect of group learning was a revelation to most participants who had previously only had negative experiences of learning in groups. They also found that sharing problems and successes with trusted others injected an additional level of excitement to the learning process, increasing motivation. 
While initially uncomfortable with the level of autonomy they were given, participants quickly adjusted to take advantage of being able to set their own learning goals and to change those goals as their understanding of the possibilities grew. The realization that they could take responsibility for their own learning and not depend on the 'teacher' to tell them what to do was instrumental in developing their learning confidence.

Many of the access obstacles for inexperienced users of the Internet, in particular those related to terminology and the protocols for using Web 2.0 tools, diminished with learning. Other types of access problems, such as the provision and compatibility of equipment, are issues to be addressed at the organizational level or even at a governmental level. Overall, the development of digital information capability for life long learning requires appropriate support to overcome a variety of obstacles facing engagement with the digital environment.

\section{References}

American Library Association. (2006). Presidential Committee on Information Literacy. Retrieved from http://www.ala.org/ala/mgrps/divs/acrl/publications/whitepapers/presidential.cfm Accessed June 20, 2009. Document ID: 126315.

Anderson, T. (2009). Teaching and learning in a net-centric world. Retrieved May 13, 2009, from http://terrya.edublogs.org/2009/04/28/social-networking-chapter/

Ashcroft, E. R. (1987). An evaluation of traditional staff development practices for implementing change in university teaching. Unpublished Ph D thesis. Ph D, Massey University, Palmerston North, New Zealand.

Assor, A., Kaplan, H., \& Roth, G. (2002). Choice is good, but relevance is excellent: Autonomy-enhancing and suppressing teacher behaviours predicting students' engagement in schoolwork. British Journal of Educational Psychology, 72, 261-278.

Baldi, S., Kutner, M., Greenberg, E., Jin, Y., Baer, J., Moore, E., . . White, S. (2009). Technical report and data file user's manual for 2003 national assessment of adult literacy. Washington: National Centre for Educational Statistics.

Bandura, A. (1977). Self-efficacy: Toward a unifying theory of behavioural change. Psychological Review, 84(2), 191-215.

Bandura, A., \& Cervone, D. (1986). Differential engagement of self-reactive mechanisms governing the motivational effects of goal systems. Organisatinal Behaviour and Human Decision Processes, 38(1), 92-113.

Birkerts, S. (1995). The Gutenberyg elegies. New York: Ballantine.

Bonk, C. J. (2009). The world is open: How Web technology is revolutionizing Education. San Francisco: Jossey-Bass.

Bozionelos, N. (2004). Socio-economic background and computer use: The role of computer anxiety and computer experience in their relationship. International Journal of Human-Computer Studies, 61(5), 725-746.

Bransford, J. D., Sherwood, R. D., Hasselbring, T. S., Kinzer, C. K., \& Williams, S. M. (1990). Anchored instruction: Why we need it and how technology can help. In D. Nix \& R. J. Spiro (Eds.), Cognition, education, and multimedia: Exploring ideas in high technology (pp. 115-141). Hillsdale, NJ: Lawrence Erlbaum Associates, Publishers.

Brown, C., Murphy, T. J., \& Nanny, M. (2003). Turning techno-savvy into infor-savvy: Authentically integrating information literacy into the college curriculum. The Journal of Academic Librarianship, 29(6), 386-398.

Brown, J. S. (2000). Growing up digital: How the Web changes work, education and the ways people learn. Change (March/April), 10-20. 
Bryman, A., \& Bell, E. (2007). Business research methods (2nd ed.). Oxford: Oxforn University Press.

Bundy, A. (2004). Australian and New Zealand information literacy framework: Principles, standards and practice (2nd ed.). Adelaide: ANZIIL. Retrieved May, 26, 2008, from http://www.anziil.org/resources/Info lit 2nd edition.pdf

Cassidy, S., \& Eachus, P. (2002). Developing the computer user self-efficacy (CUSE) scale: Investigating the relationship between computer self-efficacy, gender and experience with computers Journal of Educational Computing Research, 26(2), 133-153.

Castells, M. (2001). The Internet Galaxy: Reflections on the Internet, business and society. Oxford: Oxford University Press.

The Centre for Literacy. (n.d.). What is literacy? Retrieved June 13 2010, from http://www.centreforliteracy.qc.ca/about/literacy

Chen, M.-P., \& Wang, L.-C. (2009). The effects of type of interactivity in experiential games-based learning. In M. Chang, R. Kuo, Kinshuk, G.-D. Chen \& M. Hirose (Eds.), Learning by playing. Gamebased education system design and development. Proceedings of 4th International Conference on ELearning and Games, Edutainment (pp. 273-282). Berlin Heidelberg: Springer-Verlag.

Coglan, D., \& Brannick, T. (2002). Doing action research in your own organisation. London: Sage Publications.

Coleman, M., \& Lumby, J. (2009). The significance of site-based practitioner researcher in educational management. In D. Middlewood, M. Coleman \& J. Lumby (Eds.), Practitioner research in education: making a difference. London: Paul Chapman Publishing.

de Montigny, F., Cloutier, L., Ouellet, N., Courville, F., \& Rondeau, G. (2001). Teachers' perceptions of self-efficacy and beliefs regarding information and communications technology (ICT) Paper presented at the Society for Information Technology and Teacher Education International Conference (pp. 23022306), Chesapeake, VA.

Dewey, J. (1933). How we think. Lexington, USA: D.C. Heath and Company.

Duderstadt, J. J., \& Womack, F. W. (2004). The future of the public university in America: Beyond the crossroads. Baltimore: The John Hopkins University Press.

Eshet-Alkalai, Y., \& Chajut, E. (2010). You can teach old dogs new tricks: The factors that affect changes over time in digital literacy. Journal of Information Technology Education, 9, 173-181. Retrieved from http://www.jite.org/documents/Vol9/JITEv9p173-181Eshet802.pdf

Eshet-Alkalai, Y., \& Geri, N. (2007). Does the medium affect the message? The influence of text representation format on critical thinking. Human Systems Management, 26, 269-279.

Gokhale, A. A. (1995). Collaborative learning enhances critical thinking. Journal of Technology Education, $7(1), 22-30$.

Grant, D. M., Malloy, A. D., \& Murphy, M. C. (2009). A comparison of student perceptions of their computer skills to their actual abilities. Journal of Information Technology Education, 8, 141-159. Retrieved from http://www.jite.org/documents/Vol8/JITEv8p141-160Grant428.pdf

Halonen, R. (2008). Action learning with an information system project: Subjective reflections. Reflective Practice, 9(1), 98-99.

Haney, W., Russell, M., Gulek, C., \& Fierros, E. (1998). Drawing on education: Using student drawings to promote middle school improvement. Schools in the Middle, 7(3), 38-43.

Harel-Caperton, I. (2003). Clickerati kids: Who are they? Retrieved 22 June, 2011, from http://www.mamamedia.com/areas/grownups/new/21 learning/main.html

Hegarty, B. (2007). Three - step reflective framework and template. Retrieved 22 February, 2011, from http://wikieducator.org/Hegarty_Reflective_Framework_and_Template 
Hegarty, B., Penman, M., Brown, C., Coburn, D., Gower, G., Kelly, O., .. Moore, M. (2005). Approaches and implications of eLearning adoption in relation to academic staff efficacy and working. Palmerston North: Universal College of Learning and Ministry of Education.

Heine, C., \& O'Conner, D. (n.d.). 21 st century digital information fluency model. Retrieved April 13, 2009, from http://21cif.com/resources/difcore/

Horsburgh, M., Lamdin, R., \& Williamson, E. (2001). Multiprofessional learning: The attitudes of medical, nursing and pharmacy students to shared learning. Medical Education, 35(9), 876-883.

Hsiao, H.-C. (2009). Reflective learning through playing digital games The Sims 2. In M. Chang, R. Kuo, Kinshuk, G.-D. Chen \& M. Hirose (Eds.), Learning by playing. Game-based Education System Design and Development. Proceedings of 4th International Conference on E-Learning and Games, Edutainment (pp. 220-227). Berlin Heidelberg: Springer-Verlag.

Hunt, L. M., Eagle, L., \& Thomas, M. J. W. (2002). Student resistance to ICT in education. Paper presented at the International Conference on Computers in Education, North Shore, New Zealand.

Hunt, L. M., Eagle, L. C., \& Kitchen, P. J. (2004). Marketing education and information technology: Matching needs or needing a better match? Journal of Marketing Education, 26(1), 75-88.

Jacques, D. (1991). Learning in groups. London: Kogan Press.

Janes, J. (2007, January). Why Johnny can't search. American Libraries, p.38.

Jenson, J. D. (2004). It's the information age, so where is the information? Why our students can't find it and what we can do to help. College Teaching, 52(3), 107-112.

Jones, A., Scanlon, E., \& Blake, R. (2000). Conferencing in communities of learners: Examples from scoial history and science communication. Educational Technology \& Society, 3(3), 215-226.

Jones, Q., Rafaeli, S., \& Ravid, G. (2004). Information overload and the message dynamics of online interaction spaces: A theoretical model and empirical exploration. Information Systems Research, 15(2), 194-210.

Joo, Y.-J., Bong, M., \& Choi, H.-J. (1998). Self-efficacy for self-regulated learning, academic self-efficacy, and internet self-efficacy in web-based instruction. Educational Technology Research and Development, 48(2), 5-17.

Kohut, A., Taylor, P., Keeter, S., Parker, K., Morin, R., Cohn, D. V., . . Clement, S. (2010). Millennials: A portrait of generation next: Confident. connected. open to change. Washington, DC: Pew Research Centre.

Krause, K., Hartley, R. J., James, R., \& McInnis, C. (2005). The first year experience in Australian universities: Findings from a decade of national studies. Canberra: Australian Department of Education, Science and Training.

Krippendorff, K. (1980). Content analysis: An introduction to its methodology. Newbury Park, CA: Sage.

Leu, D. J., Jr. (1996). Sarah's secret: Social aspects of literacy and learning in a digital information age. Reading Teacher, 50(2), 162.

Littlejohn, A., Margaryan, A., \& Vojt, G. (2010). Exploring students' use of ICT and expectations of learning methods. Electronic Journal of e-Learning, 8(1), 13-20.

Manuel, K. (2002). Teaching information literacy to Generation Y. Journal of Library Administration, $36(1 / 2), 195$.

Marcum, J. W. (2002). Rethinking information literacy. The Library Quaterly, 72(1), 1-26.

Margaryan, A., \& Littlejohn, A. (2008). Repositories and communities at cross-purposes: Issues in sharing and reuse of digital learning resources. Journal of Computer Assisted Learning, 24(4), 333-347.

Margaryan, A., Littlejohn, A., \& Vojt, G. (2010). Are digital natives a myth or reality? University students' use of digital technologies. Computers and Education, 56(2), 429-440. 
Merriam, S. (1998). Research methods in education and psychology. London: Sage Publications.

Mertens, D. (1998). Research methods in education and psychology. London: Sage Publications.

Metzger, M., Flanagin, A., \& Zwarun, L. (2003). College student Web use, perceptions of information credibility, and verification behaviour. Computer Education(41), 271-290.

Milbrath, Y. L., \& Kinzie, M. B. (2000). Computer technology training for prospective teachers: Computer attitudes and perceived self-efficacy. Journal of Technology and Teacher Education, 8(4), 373-396.

Ministry of Ecomonic Development. (2008). Digital Strategy 2.0 Retrieved from http://www.digitalstrategy.govt.nz/Digital-Strategy-2/

Moller, L., Huett, J., Holder, D., \& Young, J. (2005). Examining the impact of learning communities on motivation. Quarterly Review of Distance Education, 6(2), 137-143.

OECD. (2004). Educational policy analysis 2004. Paris: OECD Publishing.

OECD. (2005). Learning a living: First results of the adult literacy and life skills survey. Paris: OECD Publishing.

OECD. (2006). Are students ready for a technology-rich world? What PISA studies tell. Paris: OECD Publishing.

Pajares, F., \& Miller, M. D. (1994). Role of self-efficacy and self-concept beliefs in mathematical problem solving: A path analysis. Journal of Educational Psychology, 86(2), 193-203.

Papert, S. (1998). Child power: Keys to the new learning of the digital century [lecture transcript]. Paper presented at the 11th Colin Cherry Memorial Lecture on Communication, Imperial College, London.

Parappilly, M., Quinton, J. S., \& Andersson, G. G. (2009). Enhancing the transition to university physics. Paper presented at the 32nd HERDSA Annual Conference: The Student Experience, Darwin.

Park, Y., \& Chen, J. (2007). Acceptance and adoption of the innovative use of smartphone. Industrial Management and Data Systems, 107(9), 1349-1365.

Pedro, F. (2007). The new millenium learners: Challenging our views on digital technologies and learning. Digital Kompetanse, 4, 244-263.

Phelps, R. (2002). Mapping the complexity of computer learning: Journeying beyond teaching for computer competency to facilitating computer. Ph D, Southern Cross University, Lismore, NSW. Retrieved from Retrieved from http://works.bepress.com/renata phelps/

Phelps, R., \& Graham, A. (2008). Developing technology together: A whole-school metacognitive approach to ICT teacher professional development. Journal of Computing in Teacher Education, 24(4), 125-133.

Piper, D. W., \& Austin, D. (2004). The influence of self-efficacy on teacher's practice of using computers in the classroom. Paper presented at the Society for Information Technology \& Teacher Education International Conference (pp. 1365-1371), Chesapeake, VA.

Prensky, M. (2001). Digital natives, digital immigrants, Part II: Do they really think differently? On the Horizon, 9(6), 1-6. Accessed 7 September, 2005 from http://www.marcprensky.com/writing/PrenskyDigitalNatives,DigitalImmigrants-Part2002.pdf

Rauhofer, J. (2008). Privacy is dead, get over it! Information privacy and the dream of a risk-free society. Information \& Communications Technology Law, 17(3), 185-197.

Riel, M. (2007). Understanding action research. Pepperdine University. Retrieved 19 November, 2009, from http://cadres.pepperdine.edu/ccar/define.html

Rosenthal, R. L. (2010). Older computer-literate women: Their motivations, obstacles, and paths to success. Educational Gerontology, 34(7), 610-626. 
Saade, R. G., \& Kira, D. (2009). Computer anxiety in e-learning: The effect of computer self-efficacy. Journal of Information Technology Education, 8, 177-191. Retrieved from http://www.jite.org/documents/Vol8/JITEv8p177-191Saade724.pdf

Saljo, R. (2010). Digital tools and challenges to institutional traditions of learning: Technologies, social memory and the performative nature of learning. Journal of Computer Assisted Learning, 26(1), 53-64.

Skinner, E. A., \& Belmont, M. J. (1993). Motivation in the classroom: Reciprocal effects of teacher behaviour and student engagement across the school year. Journal of Educational Psychology, 85, 571-581.

Snyder, I., Angus, L., \& Sutherland-Smith, W. (2002). Building equitable literate futures: Home and school computer-mediated literacy practices and disadvantage. (Cover story). Cambridge Journal of Education, 32(3), 367-383.

Stoll, C. (1995). Silicon snake oil: Second thoughts on the information highway. New York: Doubleday.

Tobias, S. (1985). Test anxiety: Interference, defective skills, and cognitive capacity. Educational Psychologist, 20(3), 135-142.

Tuckle, S. (1995). Life on the screen: Identity in the age of the Internet. New York: Simon \& Schuster.

Twenge, J. (2009). Generation changes and their impact in the classroom: Teaching Generation Me. Medical Education, 43, 398-405.

Wang, Y.-M., \& Artero, M. (2005). Caught in the Web: University student use of Web resources Educational Media International, 42(1), 71-82.

Wilson, B. G., Ludwig-Hardman, S., Thornam, C. L., \& Dunlap, J. C. (2004). Bounded community: Designing and facilitating learning communities in formal courses. The International Review of Research in Open and Distance Learning. Retrieved 14 July 2011, 5, from http://www.irrodl.org/index.php/irrodl/article/view/204/286

Yi, Y., \& Hwang, G. J. (2003). Predicting the use of web-based information systems: Self-efficacy, enjoyment, learning goal orientation, and the technology acceptance model. International Journal of Human-Computer Studies, 59(4), 431-449.

\section{Biographies}

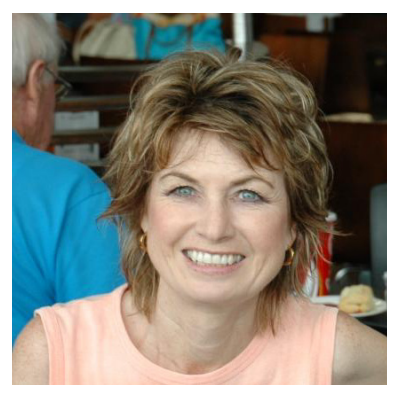

Lynn Jeffrey is an Associate Professor at the School of Management in Massey University (New Zealand). Her PhD is in learning psychology. She has a particular interest in improving adult and tertiary learning, and the role that technology might play in achieving that end. Technology that she's developed includes a computer-based, examination-on-demand system (CALES) which was used by the New Zealand Civil Aviation Authority for pilot theory examinations; a learning style website that can be used by tertiary students to get advice on improving their learning, and by their teachers for developing more relevant teaching methods; and a learning style evaluation website for workplace training. Her current research focuses on student engagement in blended learning environments, occupational competency identification and teaching international students. 

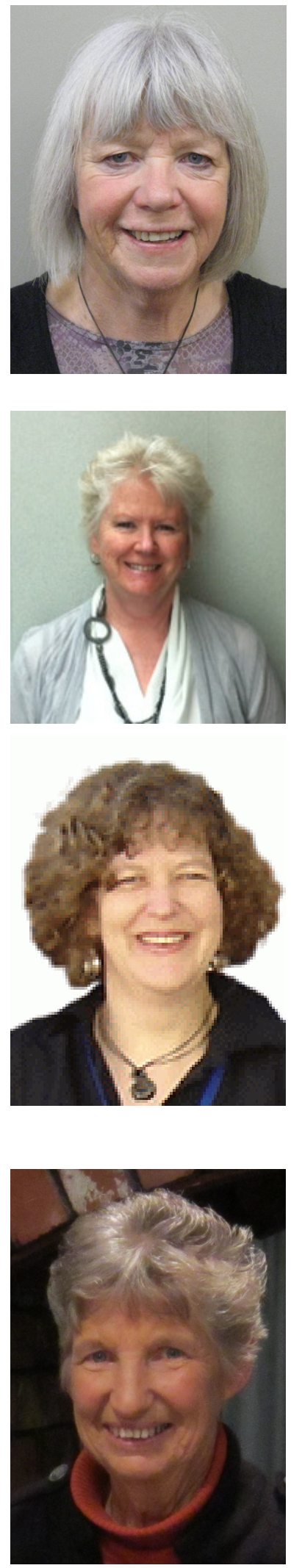

Bronwyn Hegarty is an Educational Developer at Otago Polytechnic with a dual teaching and educational design roles. She teaches courses on educational design for flexible blended learning and evaluation of eLearning for effective practice. She is involved in managing educational design projects and facilitates staff development for using technology for teaching and learning, for example, ePortfolios, web 2.0 and audio-visual approaches. Bronwyn recently submitted her thesis for a Doctorate in Education, and is very interested in professional learning and reflective practice, and their relationship to ePortfolios. She has led national research projects that have investigated self-efficacy in eLearning, and the development of digital information using Web 2.0 strategies.

Oriel Kelly is the Manager, Institute Academic Projects at Manukau Institute of Technology. A staff developer, she works with lecturers to shift their teaching to a more technology supported approach, advising on the embedding of "fit for purpose" learning technologies in the programmes they teach. Oriel is the programme leader and teacher of an online qualification for teachers and is currently leading a blended learning project for the institute. Her research interests include the use of educational technologies, digital information literacy skills and staff development, and in 2002 she won one a New Zealand national Tertiary Teaching Excellence Award for innovation.

Merrolee Penman is Principal Lecturer in the School of Occupational Therapy, Otago Polytechnic. Her research interests are centred around learning, whether that be the learning of students in the the preprofessional programmes, or the learning of occupational therapists in practice. Related to this, Merrolee's other key research interests are in the use of digital information literacy, and how technology can be used to support and enable learning.

Dawn Coburn was until 2008 a senior lecturer at the University of Otago College of Education. She then continued to engage in research activity involving the Otago Polytechnic and the University of Otago as well as undertaking doctoral studies. Her research interests include teacher education, technology education, e-learning and the impact of changes from film-based to digital photography. Dawn now lives in a rural area where her strong interests include working with the local museum and community garden groups. 


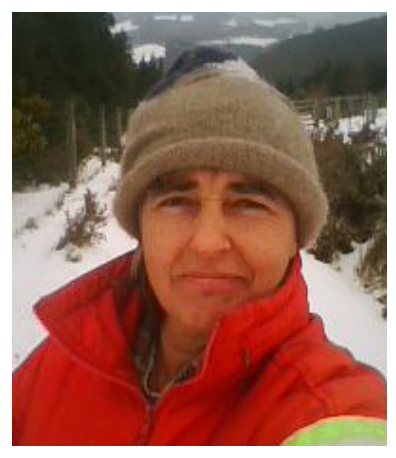

Jenny McDonald is a Lecturer in the Higher Education Development Centre at the University of Otago. Jenny's main research interest is exploring how teaching and learning can be enhanced or supported through the use of technology. She has particular interest in the application of natural language processing tools and techniques for educational research and practice. 